\title{
PONTOS CRÍTICOS NA PRODUÇÃO CIENTÍFICA DE ENFERMAGEM - OS¹ TRABALHOS SUBMETIDOS À REBEn
}

\author{
CRITICAL ASPECTS OF THE SCIENTIFIC RESEARCH ON NURSING SUBMITTED TO REBEn \\ (BRAZILIAN JOURNAL OF NURSING)
}
PUNTOS CRIITICOS EN LA PRODUCCIÓN CIENTÍFICA DE ENFERMERÍA - LOS TRAJAJOS SOMETIDOS ALAREBEn

Joel Rolim Mancia²

Flávia Regina Souza Ramos ${ }^{3}$

\begin{abstract}
RESUMO: Estudo exploratório descritivo que objetivou detectar pontos críticos de manuscritos submetidos à avaliação para publicação na Revista Brasileira de Enfermagem. A coleta de dados se deu a partir de instrumentos de avaliação utilizados pelo Conselho Editorial da Revista Brasileira de Enfermagem, dos quais estudou-se 32 pareceres favoráveis à publicação, correspondentes a $50 \%$ dos textos publicados em um volume da revista. Os resultados demonstram que a totalidade dos textos aprovados para divulgação apresentavam deficiência e necessidade de correções, em torno das quais foi possivel apresentar requisitos e orientações que auxiliam os autores no encaminhamento de suas produções para periódicos com sistema de revisão por pares. Ainda aparece como uma questão importante o desconhecimento por parte dos autores das normas de publicação do periódico.
\end{abstract}

PALAVRAS-CHAVE: publicações em enfermagem, periódicos, editoração, normas de publicação

ABSTRACT: This is an exploratory descriptive study which aims at detecting critical aspects of the manuscripts submitted to REBEn (Brazilian Journal of Nursing) for publishing. Data was collected through the evaluation instruments used by the Editorial Board of REBEn on the selection of articles for the journal. Thirty- two evaluation reports, which represent $50 \%$ of the articles published in one volume of the journal, were analyzed. Results showed that most of the articles accepted for publishing were deficient, needed correction and that the authors needed guidance regarding requirements for publishing, such as peer review. Another problem detected was that the authors of the articles submitted did not seem to know the norms of presentation of the journal.

KEYWORDS: publishing in nursing, journals, publishing, norms of publishing

RESUMEN: Estudio exploratorio descriptivo que tuvo como objetivo detectar los puntos críticos de manuscritos que se someten a una evaluación para publicarlos en la Revista Brasileña de Enfermería. Se recogieron los datos a partir de instrumentos de evaluación utilizados por el Consejo Editorial de la Revista, de los cuales se estudiaron 32 pareceres favorables a la publicación, que correspondieron a los $50 \%$ de los textos publicados en un volumen de la Revista. Los resultados han demostrado que la totalidad de los textos que se aprueban para la divulgación presentan deficiencia y necesidad de correcciones; por eso ha sido posible presentar dentro del estudio requisitos y orientaciones que auxilian a los autores a encaminar sus producciones, con un sistema de revisión por pares. Aún aparece como un dato importante el desconocimiento por parte de los autores de las normas de publicación del periódico.

PALABRAS CLAVE: publicaciones en enfermeria, periódicos, editoración, normas de publicación

Recebido em 23/03/2002

Aprovado em 26/06/2002

\footnotetext{
1 Texto produzido a partir do trabalho apresentado no $4^{\circ}$ Encontro Nacional de Editores de Periódicos de Enfermagem, realizado durante $053^{\circ}$ Congresso Brasileiro de Enfermagem em Curitiba, 2001.

2 Enfermeiro. Mestre em enfermagem pela UFSC. Servidor da Prefeitura Municipal de Porto Alegre.

${ }^{3}$ Enfermeira. Doutora em Enfermagem. Professora do Departamento de Enfermagem da UFSC.
} 


\section{INTRODUÇÃO}

É unânime o reconhecimento da importância dos periódicos científicos para a formação do pesquisador e o desenvolvimento das mais diversas disciplinas e áreas do conhecimento, sendo que, para o atendimento desta demanda, os periódicos têm se pautado em certos critérios editoriais, que consideram os aspectos técnicos normativos da revista, a qualidade gráfica, a melhor qualidade do texto e o máximo de qualidade científica. Para tal deve contar com claros parâmetros, trabalho profissional especializado e uma arbitragem rigorosa e construtiva, com vistas à excelência de seu conteúdo. (TRZESNIAK, 2001)

O sistema de arbitragem consiste na avaliação institucionalizada e criteriosa, através da leitura crítica dos pares (referee traduzido como árbitro, avaliador, parecerista, consultor) que assessoram na aceitação de manuscritos (relato impresso) submetidos para publicação (manuscritos legitimados pela competente avaliação por pares). (PESSANHA, 1998, discutindo ZUCKERMAN; MERTON).

A necessidades de organizar e selecionar o material a ser publicado fez surgir os dois principais atores no processo de avaliação: o editor e os avaliadores que, somados ao autor, formam o elenco de sujeitos responsáveis pela publicação científica. À parte das inegáveis vantagens de um sistema de arbitragem, é importante não desconhecer as criticas geradas por eventuais distorções no seu desenvolvimento, ou seja, pela possibilidade de erros de julgamento e avaliação, como aqueles motivados por propensão negativa ou positiva a certos temas devido a conflitos de interesses, argumentos preconceituosos sobre minorias, má conduta ética de editores e avaliadores ou, ainda, pelo próprio aumento do tempo entre a apresentação e a divulgação do material científico. Para enfrentar a possibilidade de tais problemas, são aplicados procedimentos que vão desde a declaração de compromisso dos avaliadores até o controle entre avaliadores (usando o maior número de árbitros) e controle dos pareceres pelo próprio editor da publicação. Além disso, são fundamentais a utilização de claros critérios norteadores de julgamento, a possibilidade de diálogo respeitoso entre autor e avaliador (incluindo o direito do autor recorrer da decisão) e a garantia do caráter confidencial do processo (PESSANHA, 1998).

O reconhecimento da necessidade e dos limites de um sistema de arbitragem deve ser constantemente relacionado ao reconhecimento das necessidades e limites da própria prática de pesquisadores e autores em sua tarefa de produção e divulgação científica. Esta, por sua vez, se relaciona a inúmeros fatores, como a formação do pesquisador, a tradição e experiência das comunidades científicas e dos veículos de divulgação, a discussão interna e externa para a definição coletiva de políticas editoriais coerentes aos interesses da área. Por toda esta complexa atuação de determinantes no estágio de desenvolvimento da qualidade da publicação científica de uma área, emerge uma adicional responsabilidade ou missão educativa dos veículos de divulgação, a de contribuir para o aprimoramento e maior qualidade da produção científica através do maior diálogo entre os diversos atores do processo de publicação (avaliadores e autores).

Tal caráter educativo do processo de avaliação já é notório, sendo debatido no meio editorial. Greene (2001), por exemplo, reconhece funções adicionais das revistas científicas nos paises em desenvolvimento, como as de estabelecer e implementar critérios de qualidade para a divulgação científica, ajudar a consolidar áreas de pesquisa e treinar revisores e autores em análise crítica e melhoramento da qualidade da ciência, além das suas já tradicionais funções (ser memória da ciência, divulgar os produtos da pesquisa para a comunidade científica e sociedade e fornecer parâmetros para avaliação da produção de cientistas e instituições) (MANCIA,2001)

O reconhecimento destas especiais responsabilidades impõe não apenas à efetiva comunicação entre autores e avaliadores, para o aprendizado de ambos, mas a busca de estratégias que ampliem a abrangência e impacto destas ações educativas. Estas estratégias podem incentivar debates mais amplos com toda a comunidade científica de áreas específicas, abertas à participação de pesquisadores, professores e profissionais em formação, com vistas a definição de ações impactantes sobre as políticas e projetos editoriais (necessidades e resultados esperados dos veículos de divulgação), políticas e projetos científicos (prioridades e linhas de pesquisa) e políticas e projetos de formação (necessidades, potenciais e desafios a nivel de graduação e pós-graduação).

A expectativa deste artigo se faz, exatamente, no esforço de divulgar alguns pontos críticos revelados no processo de avaliação da produção científica, submetida à arbitragem por pares na Revista Brasileira de Enfermagem, acreditando-se que estes sejam indicadores significativos das principais dificuldades enfrentadas por autores na aceitação de seus trabalhos para publicação.

\section{METODOLOGIA}

O estudo delineou-se como exploratório descritivo, a partir da análise de dados obtidos em fonte documental da Revista Brasileira de Enfermagem.

A REBEn foi criada em 1932 e permaneceu, por quase quatro décadas, como o único periódico da enfermagem brasileira. É o orgão oficial de divulgação da Associação Brasileira de Enfermagem, comprometido com a divulgação da produção científica de interesse da profissão e do projeto político da entidade. Está classificada no QUALIS/CAPES como periódico Nacional A; consta das seguintes bases de dados: MEDLINE/INI, CINAHAL, LILACS e BDENF, portanto, atende às exigências de admissão nestas bases de dados, quanto a caráter científico, arbitragem por pares, conselho editorial, periodicidade, duração, pontualidade e normalização. Utiliza a ABNT como norma oficial e aceita textos em português, inglês e espanhol; publica originais de autores assinantes da revista, desde que ajustados às normas de publicação. A seleção dos artigos com vistas à divulgação se dá por meio de pareceres de, no minimo, dois consultores.

$\mathrm{Na}$ REBEn utiliza-se um instrumento de acompanhamento dos textos, desde seu ingresso na secretaria até a aprovação final para publicação. É um formulário constituido de duas partes, a primeira consta de questões fechadas que são respondidas pela secretaria da revista e pelo avaliador. A segunda parte do documento tem 
questões abertas de exclusiva responsabilidade dos avaliadores. $O$ documento recebe um número e o nome do manuscrito, de forma que autor e avaliador não sejam identificados. Condição esta mantida durante todo o processo de avaliação. Os instrumentos se constituem em fonte de consulta, bem como subsídio para proposição da política editorial, o que é de conhecimento dos avaliadores. Após aprovação do texto na forma de artigo, é solicitado aos autores a cessão de direitos autorais para a Revista Brasileira de Enfermagem; as declarações, quando couber, de respeito às normas brasileiras de pesquisas que envolvem seres humanos e de autorização institucional para a realização de estudo.

Para este estudo foi selecionado um parecer de cada um dos 32 originais indicados para publicação, correspondentes a $50 \%$ dos artigos publicados em um volume do periódico ( 4 fascículos/ 64 trabalhos publicados).

\section{UMA REFLEXÃO EM TORNO DOS DADOS ANALISADOS}

\section{PONTOS CRÍTICOS EM RELAÇÃO AO RESUMO E TÍTULO}

Com a enorme expansão da produção e acesso à informação (e sua rápida obsolescência), as atuais formas de comunicação da comunidade científica (revistas, meios eletrônicos, eventos, entre outros) e os modernos meios para a realização de levantamentos bibliográficos, títulos, palavraschave e resumos ganham importância como elementos orientadores da escolha e direcionamento dos leitores, que enfrentam a impossibilidade de uma seleção baseada na leitura integral de todas as informações disponiveis.

Apesar desta seção de um artigo nem sempre receber a devida importância e tratamento cuidadoso são conhecidas as orientações acerca do conteúdo básico de um resumo, incluindo uma breve declaração do objetivo e de sua relevância, a abordagem metodológica, os resultados obtidos, uma clara declaração das principais conclusões e informações adicionais sobre a credibilidade dos resultados ou a organização do artigo. (GREENE, 2001).

Os dados analisados neste estudo demonstraram, como pontos críticos, os seguintes problemas dos títulos e resumos:

- ausência ou insuficiência de aspectos/conteúdos importantes para despertar o interesse do leitor;

- conteúdo que não guarda coerência com o trabalho apresentado;

- não obediência às recomendações quanto ao número de palavras (principalmente excesso de palavras no titulo);

- precárias traduções para línguas estrangeiras (tradução "dicionarizada").

PONTOS CRÍTICOS EM RELAÇÃO AO REFERENCIAL TEÓRICO

De início, é preciso destacar a importância da clara explicitação do referencial teórico de um estudo. Com base no modo como os pesquisadores estabelecem a imprescindivel relação teoria e método, torna-se possivel a construção de um objeto de pesquisa a partir de um dado empírico ou realidade, ou seja, o referencial teórico orienta o percurso do pensamento e da busca de um conhecimento novo.

De acordo com os pareceres de analistas estudados, os principais problemas, neste aspecto, se referem a:

- referencial teórico ausente;

- referencial teórico pouco explorado;

- referencial teórico explicitado mas não visível, ou não utilizado ao longo do trabalho.

Estes achados confirmam as críticas de Silva e Ramos (2001) que, ao analisarem os resumos 376 teses de doutorado, defendidas no período de 1972 a 1999, e publicadas nos catálogos de "Informações sobre Pesquisas e Pesquisadores em Enfermagem", constataram que cerca de $31 \%$ ou quase um terço dos trabalhos não explicitavam seus referenciais, ou o faziam de modo insuficiente e sem clareza. Nas abordagens "qualitativas" (termo usado de modo genérico ou limitado ao emprego de certas técnicas, como a entrevista) $50 \%$ dos resumos não explicitavam claramente seus referenciais teórico-metodológicos. Estes dados podem revelar problemas na elaboração dos resumos, na própria definição e apresentação do referencial teórico-metodológico, ou em ambas os componentes.

\section{PONTOS CRÍTICOS EM RELAÇÃO AOS OBJETIVOS}

A definição dos objetivos de uma pesquisa e de uma comunicação científica é fundamental como base para decisões metodológicas e operacionais do estudo, bem como para sustentar o alvo ou "ao que se pretende chegar" com aquele empreendimento. Apesar de elemento elementar, muitas vezes algumas dificuldades prejudicam uma clara compreensão por parte do leitor. Os dados levantados mostraram problemas quanto a objetivos que:

- só aparecem no resumo e não no corpo do texto;

- são apontados no corpo do trabalho mas não explicitados no resumo;

- não são devidamente trabalhados ou apenas parcialmente atendidos nas discussões e resultados relatados ou, ao contrário, os resultados extrapolam os objetivos traçados;

- deficiente relação entre os conteúdos analisados e os objetivos apresentados.

Tais problemas levantam questionamentos quanto a imprecisões na forma de redigir relatórios ou mesmo falhas metodológicas que podem comprometer todo o percurso metodológico do estudo (objeto mal delimitado levando a objetivos vagos, imprecisos ou incorretos, conseqüentes erros nas opções metodológicas, incorrendo em perda da qualidade e mérito do estudo).

O estudo de Marziale e Mendes (2002) discute a qualidade dos manuscritos submetidos à Revista Latinoamericana de Enfermagem, segundo opinião de seus consultores e, quanto aos objetivos, apontam a definição vaga e desarticulada, a falta de clareza na sua elaboração e a utilização incorreta do tempo verbal.

\section{PONTOS CRÍTICOS EM RELAÇÃOÀ METODOLOGIA}

As informações metodológicas devem ser claras e suficientes para demonstrar as escolhas, instrumentos e procedimentos usados pelo pesquisador, de modo a permitir 
que tal abordagem seja repetida/replicada, avaliada, criticada e ou aperfeiçoada. Mesmo em estudos não experimentais, qualitativos, relatos de experiências ou revisões e reflexões, algumas informações devem dar conta dos processos utilizados pelo autor para chegar a seus resultados, propostas ou proposições, apresentando suas bases e perspectivas, seus limites e a contextualização dos mesmos considerando o tempo, espaço e sujeitos envolvidos.

Os principais pontos críticos em relação a metodologia, nos pareceres analisados, foram:

- não informam sobre critérios de escolha dos sujeitos;

- informações insuficientes sobre procedimentos de coleta de dados;

- não descrevem adequadamente os instrumentos ou aspectos abordados em entrevistas;

- não situam temporalmente os dados do estudo.

\section{PONTOS CRÍTICOS EM RELAÇÃO AOS ASPECTOS ÉTICOS}

O principal problema apontado nos pareceres dos analistas, em relação aos aspectos éticos de um estudo a ser publicado, refere-se ao:

-não atendimento das recomendações da Resolução CNS 196/96 - Normas de pesquisa envolvendo seres humanos, principalmente quanto à informação sobre a obtenção do consentimento livre e esclarecido dos sujeitos da pesquisa.

A detecção deste problema pode estar relacionada a várias possiveis explicações: - uma recente preocupação do meio científico com a divulgação da resolução citada, já que a mesma estabelece as diretrizes à proteção dos sujeitos da pesquisa em qualquer campo do conhecimento e tipo de pesquisa, além de definir os alicerces dos Comitês de Ética em Pesquisa (CEPs) e do Conselho Nacional de Ética em Pesquisa (CONEP), constituindo uma necessidade e uma conquista de muitos anos de discussão; - uma dificuldade na avaliação crítica dos elementos éticos de uma estudo, gerada pela pouca experiência ou consenso no meio científico interno (da área de enfermagem) ou mesmo carência na formação de seus pesquisadores; - um conhecimento atualizado e abrangente da referida Resolução por parte dos árbitros, permitindo que os problemas a ela relacionados sejam mais facilmente identificados; - uma utilização de critérios insuficientes para julgamentos destes aspectos, por carência de informações quanto às múltiplas varáveis ou componentes da relação ética e pesquisa.

Como o presente estudo não pode concluir sobre os parâmetros e o rigor com que os aspectos éticos estão sendo avaliados, apenas deve ressaltar a abrangência e complexidade destas questões, que envolvem: - o protocolo, o projeto e os fins da pesquisa (impactos, necessidades, interesses, entre outros); - as fontes e uso de recursos; - a metodologia (métodos e técnicas, seleção de sujeitos e amostra, avaliação da efetividade e necessidade procedimentos com os participantes, etc); - os participantes (consentimento livre e esclarecido, avaliando vulnerabilidades, condições de explicitar a vontade, qualidade da informação e legitimidade, bem como respeitando direitos, anonimato, sigilo e especificidades dos envolvidos); - as relações entre os pares (veracidades, confiabilidade, fidedignidades, direitos autorais, etc); - a divulgação dos resultados (responsabilidade autoral e editorial); - as responsabilidades e deveres do pesquisador (competência, sensibilidade, respeito aos direitos).

Segundo Secaf (2000) os aspectos éticos e legais que envolvem a publicação científica dizem respeito a:

- Direitos do ser humano:

- princípios éticos (respeito pela pessoa, beneficência, justiça, fidelidde, veracidade, confidencialidade);

- direitos dos sujeitos (de não sofrer efeitos negativos ou danosos, do conhecimento pleno, da auto-determinação, da intimidade, anonimato e confidencialidade);

- diretrizes éticas internacionais;

- documentos regulamentadores nacionais (Constituição de 1988, Códigos Civil e Penal, Códigos dos Direitos do Consumidor, Res. CNS 196/96, Estatuto da criança e do adolescente e outros decretos e leis específicas).

- Direitos Autorais:

- Definição de autoria, múltipla autoria e participações; definição de fraude, plágio, contrafação; atentado aos direitos morais (inclui direitos de paternidade, nominação, divulgação, integridade, modificação e arrependimento relacionado a obras) e patrimoniais.

Para Arcuri (1994), as causas de condutas eticamente inadequadas em pesquisa podem ser de caráter individual, grupal, organizacional e, também, editorial, podendo ser relacionadas desde a posturas desonestas até a ignorância de normas e regras legais e do meio científico. Dentre as condutas obscuras, a autora discute a fraude como uma das mais comuns, em suas variadas formas: plágio, dados forjados, falsificação (autoria), meios obscuros para garantir a coleta, preconceitos, dados seletivos, conduta trivial e dados falsificados.

Evidencia-se, assim a grande responsabilidade de instituições formadoras, entidades científicas e órgãos de classe no preparo, quanto aos aspectos éticos em pesquisa, de profissionais (autores e consumidores), promovendo o acesso a informações atualizadas e corretas, a discussão e desenvolvimento de orientações, guias e códigos consensuados e que articulem as pautas e critérios gerais da ciência com as especificidades das diversas áreas e disciplinas, bem como com as formas de controle sobre os processo e produtos da ciência. Tal responsabilidade é reafirmada pelas recomendações de diversos estudos, como os de Watanabe et al. (1985), Secaf e Schmidt (1986) e Arcuri (1994).

PONTOS CRÍTICOS EM RELAÇÃO À DISCUSSÃO/ ANÁLISE DOS DADOS/RESULTADOS E CONSIDERAÇÕES FINAIS

A discussão e análise dos dados de uma pesquisa ou o conteúdo descritivo e argumentativo de uma reflexão ou relato de experiência é, sem dúvida, o componente de um artigo científico que costuma exigir a atenção de autores e leitores. Isto não significa que apresente qualquer independência em relação aos outros requisitos de uma comunicação científica, ou mesmo que a preocupação com tal capitulo reverta em uma qualidade privilegiada do mesmo. 
Na verdade, as críticas demonstram que grande parte das características dos manuscritos de qualidade precária se deve a problemas relacionados a este aspecto, como apontam os estudos de Greene (2001), Marziale e Mendes (2002).

No presente estudo, os principais problemas detectados nos manuscritos pelos avaliadores foram:

- exploração insuficiente do referencial teórico na análise;

- exploração insuficiente dos autores citados ou precária relação com a literatura na análise;

- exploração insuficiente dos dados e achados na análise;

- ausência ou insuficiência de comentários ou conclusões sobre o conjunto do trabalho nas considerações finais.

- ausência de indicativos para novos trabalhos.

Torna-se evidente a relação entre qualidade da discussão/análise e qualidade da revisão bibliográfica, ou mesmo das opções metodológicas do estudo, sendo o momento da análise bastante revelador das fragilidades e potencialidades de todo o processo de estudo. Além disso, principalmente em comunicações de investigações, ficam reveladas as inadequações entre resultados obtidos e interpretações e conclusões apresentadas, podendo incidir, inclusive em distorções éticas por parte do autor. Tais distorções ocorrem tanto por inexperiência por parte do autor como por irresponsabilidade, preconceito, manipulação e precipitações que prejudicam o imprescindivel juízo e coerência na relação entre dados/resultados e interpretações. Do mesmo modo, a inexperiência pode levar o autor, para evitar tais riscos, a se eximir de maior explicitação de seu pensamento e capacidade reflexiva. A superficialidade, então ocasionada, pode ser relacionada aos pontos críticos mencionados acima.

Assim, destaca-se a maturidade científica dos autores no desenvolvimento de um pertinente diálogo entre outros autores, informações/dados apresentados e sua própria capacidade argumentativa e elucidativa, imprescindivel ao exercício crítico e à consolidação de uma comunidade científica. Também a síntese final de um estudo, com claras indicações de seus limites, contribuições e potenciais de continuidade na construção do conhecimento e enfrentamento de problemáticas de uma profissão, representa uma manifestação de consideração para com a comunidade a qual se integra.

\section{PONTOS CRÍTICOS EM RELAÇÃO ÀS REFERÊNCIAS, CITAÇÕES E ILUSTRAÇÕES}

Apesar das normas técnicas relacionadas à apresentação de citações e referências bibliográficas, bem como de ilustrações (tabelas, gráficos, figuras e fotos) possuam uma ampla divulgação no meio acadêmico, pontos críticos referentes a tais apresentações ainda são comumente encontrados, como:

- não atendimento às normas da ABNT, principalmente quando: autores referenciados não constam do corpo de trabalho ou são citados e não referenciados; citações literais sem os requisitos necessários;

- ausência de distinções gráficas entre quadros, tabelas, gráficos ou não atendimento de suas condições de apresentação;

- apresentação desnecessária ou excesso de ilustrações que poderiam ser convertidas em texto.

Se as informações quanto a estas normas são de fácil acesso, pode-se questionar sobre as causas de tais problemas, inclusive sobre uma possivel alegação de descuido ou menor atenção dos autores nestes aspectos ou, ainda, menor experiência na elaboração de manuscritos e carência de apoio técnico especializado.

\section{PONTOS CRÍTICOS EM RELAÇÃO ÀS NORMAS DE PUBLICAÇÃO DA REVISTA}

Considerações semelhantes ao item anterior podem ser feitas em relação às dificuldades de atendimento às normas de publicação do periódico. Assim, destacam-se problemas como:

- inadequação entre número de páginas especificado e o tipo de trabalho, bem como na própria classificação do mesmo (como pesquisa, revisão, relato de experiência, ensaio, resumo, entre outros);

- inadequação do resumo quanto ao número de palavras;

- inadequação quanto a apresentação das credenciais dos autores.

As normas de publicação de uma revista, embora muitas vezes banalizadas e negligenciadas, representam exigências necessárias ao exercício judicioso e objetivo do poder do editor quanto à decisão de publicação de um original (PESSANHA, 1998) e, principalmente, de sua responsabilidade para com a qualidade editorial do periódico e da divulgação científica da área a qual atende.

\section{PONTOS CRÍTICOS EM RELAÇÃO À REDAÇÃO}

A redação científica, além das qualidades essenciais de uma expressão do pensamento, como a correção, clareza, harmonia, originalidade e vigor, diferencia-se por ser denotativa e não conotativa, portanto, exigindo clareza, precisão e concisão, não admitindo ambigüidades e não prescindindo de elevação da linguagem (BARRADAS, 2001). Tais condições são necessárias a qualquer tipo de trabalho científico, sejam teses, artigos completos ou resumos para apresentações em eventos.

Os problemas mais apontados pelos consultores, quanto à redação e linguagem, se referiram a:

- erros quanto a concordância (verbal e nominal);

- inadequações e variações quanto ao tempo empregado ao longo do texto;

- falhas quanto à clareza.

A falta de clareza e precisão na redação científica é um dos problemas mais comuns e, na maioria dos casos, relaciona-se a aspectos que poderiam ser facilmente resolvidos pela consulta aos recursos adequados (dicionários e livros de gramática da língua portuguesa), para a correção dos significado das palavras, composição dos termos das orações, pontuação, limitação de vocabulário, repetições e usos de termos desnecessários, entre outros. Infelizmente, tal consulta não é habitual, talvez por uma banalização do domínio da língua como condição secundária no preparo e 
formação de profissionais e pesquisadores.

\section{CONSIDERAÇÕES FINAIS}

Apesar dos pontos críticos aqui descritos já serem bem conhecidos e até freqüentemente relatados por acadêmicos iniciantes na produção científica, cabe reconhecer a não existência de modelos e receitas mágicas, mas a responsabilidade compartilhada entre os diversos atores do processo de construção e socialização do conhecimento - autores, editores e consumidores - no aprimoramento da qualidade dos meios de divulgação científica.

Os problemas relatados não são isolados, mas também identificados e apontados por outros editores, nacionais e internacionais, apesar das grandes diversidades de experiências e condições, bem como dos cenários específicos de países e áreas de conhecimento.

Ao apresentar tais reflexões, deseja-se motivar um mais efetivo enfrentamento das atuais dificuldades, incorporando o compromisso de uma entidade organizativa e científica como a ABEn, através do envolvimento de muitos autores, consultores e editores que contribuem para a sólida competência da Revista Brasileira de Enfermagem e para a ampliação das condições de desenvolvimento da enfermagem.

\section{REFERÊNCIAS BIBLIOGRÁFICAS}

ARCURI, E. A. M. Pesquisa em enfermagem: estudo atual e questões éticas. Texto Contexto Enf., Florianópolis, v. 3, n.1, p.20-29, jan./jun. 1994.

BARRADAS, M. M. Redação científica. In.: ASSOCIAÇÃO BRASILEIRA DE EDITORES CIENTÍFICOS. I Curso de editoração científica. Brasilia: ABEC/GDF/FEPECS, 2001.

GREENE, L. J. O trabalho científico: enfoque do editor. In.: ASSOCIAÇÃO BRASILEIRA DE EDITORES CIENTÍFICOS. I Curso de editoração científica. Brasília: ABEC/GDF/FEPECS, 2001.

MANCIA,J.R. Editorial. Rev. Bras. Enferm.,v.54, n.1, p.136-137, jan./ mar. 2001.

MARZIALE, M. H. P.; MENDES, I. A. C. Perfil da produção de uma publicação científica: revista latino-americana de enfermagem. Rev. Bras. Enferm., v. 55, n.1, 87-95, jan./fev. 2002. No prelo.

PESSANHA, C. Critérios de avaliação científica: notas para discussão. Ci. Inf., v.27, n.2, Brasília, 1998. Disponivel em: <http;/ /uww.scielo.br>. Acesso em: 11 dezembro 2000.

SILVA, A. L. da.; RAMOS, F. R. S. As linhas epistemológicas do conhecimento científico. In: SEMINÁRIO NACIONAL DE PESQUISA EM ENFERMAGEM, 10., 2001. Belém. Anais... Belém: ABEn, 2001.

SECAF, V. Artigo científico: do desafio à conquista. São Paulo: Reis Editorial, 2000.

SECAF, V.; SCHMIDT, M. J. Publicações científicas de enfermagem: direitos autorais. Rev. Paul. Enf., São Paulo, v.6, n. 4, p. 166-170, out./dez. 1986.

TRZESNIAK, P. A concepção e a construção da revista científica. In.: ASSOCIAÇÃO BRASILEIRA DE EDITORES CIENTÍFICOS. I Curso de editoração científica. Brasilia: ABEC/GDF/FEPECS, 2001.

WATANABE, E. et al. Aspectos éticos e legais da pesquisa em enfermagem. Rev. Paul. Enf., São Paulo, v.5, n. 2, p. 54-59, abr./ jun. 1985. 